\title{
Physical Activity, Physical Well-Being, and Psychological Well-Being: Associations with Life Satisfaction during the COVID-19 Pandemic among Early Childhood Educators
}

\author{
Ken Randall ${ }^{1, * \mathbb{D}}$, Timothy G. Ford ${ }^{2}$, Kyong-Ah Kwon ${ }^{3}$, Susan S. Sisson ${ }^{4}$, Matthew R. Bice ${ }^{5}$, Danae Dinkel ${ }^{6}$ (D) \\ and Jessica Tsotsoros 1
}

Citation: Randall, K.; Ford, T.G.; Kwon, K.-A.; Sisson, S.S.; Bice, M.R.; Dinkel, D.; Tsotsoros, J. Physical Activity, Physical Well-Being, and Psychological Well-Being:

Associations with Life Satisfaction during the COVID-19 Pandemic among Early Childhood Educators. Int. J. Environ. Res. Public Health 2021, 18, 9430. https://doi.org/10.3390/ ijerph18189430

Academic Editor: Paul B. Tchounwou

Received: 9 July 2021

Accepted: 26 August 2021

Published: 7 September 2021

Publisher's Note: MDPI stays neutra with regard to jurisdictional claims in published maps and institutional affiliations.

Copyright: (C) 2021 by the authors Licensee MDPI, Basel, Switzerland. This article is an open access article distributed under the terms and conditions of the Creative Commons Attribution (CC BY) license (https:/ / creativecommons.org/licenses/by/ $4.0 /)$.
1 Department of Rehabilitation Sciences, College of Allied Health, University of Oklahoma Schusterman Center, 4502 East 41st Street, Tulsa, OK 74135, USA; Jessica-Tsotsoros@ouhsc.edu

2 Department of Educational Leadership and Policy Studies, Jeanine Rainbolt College of Education, University of Oklahoma Schusterman Center, 4502 East 41st Street, Tulsa, OK 74135, USA; tgford@ou.edu

3 Department of Instructional Leadership and Academic Curriculum, Jeanine Rainbolt College of Education, University of Oklahoma, 820 Van Vleet Oval, Norman, OK 73019, USA; kkwon@ou.edu

4 Department of Nutritional Sciences, College of Allied Health, University of Oklahoma Health Sciences Center, 1200 North Stonewall Avenue, Oklahoma City, OK 73104, USA; Susan-Sisson@ouhsc.edu

5 Department of Kinesiology and Sport Sciences, University of Nebraska at Kearney, 2504 9th Ave, Kearney, NE 68849, USA; bicemr@unk.edu

6 School of Health and Kinesiology, College of Education, Health, and Human Sciences, University of Nebraska at Omaha, H \& K Building, 6001 Dodge Street, Omaha, NE 68182, USA; dmdinkel@unomaha.edu

* Correspondence: Ken-Randall@ouhsc.edu

Abstract: Seeking personal well-being and life satisfaction during a global pandemic can be daunting, such is the case for early care and education teachers who were considered non-health care essential workers during the COVID-19 pandemic. The potential changes in their physical activity, along with their overall physical and psychological well-being, may have ultimately influenced their life satisfaction. These changes included the potential for increased sedentary behaviors. Despite the high health risks associated with these factors during the pandemic, the role of physical activity in early care and education teachers' well-being and life satisfaction remains largely unknown. The purpose of this study is to examine the associations of physical activity and sedentary behaviors with teacher well-being and life satisfaction during the COVID-19 pandemic. In doing so, we explored two competing models of the relationship between the teachers' physical activity, wellbeing, and life satisfaction, one with physical activity as a mediator and the other with teachers' well-being as a mediator. An online survey, that collected information on physical, psychological, and professional well-being, job demands, and life satisfaction, was completed by 1434 US ECE teachers in 46 states. To test our hypothesized models, we conducted confirmatory factor analyses, followed by structural equation modeling. Of the respondents, $77 \%$ were overweight or obese and only $39 \%$ met the recommended $150 \mathrm{~min}$ of moderate physical activity per week. They had a mean life satisfaction score that qualifies as slight satisfaction, they experience moderate stress, and, collectively, are approaching the threshold for depression yet still reflect moderate-to-high work commitment. The empirical test of our competing mediation models found the model where teacher well-being mediated the association between physical activity, sedentary behavior, and life satisfaction was the superior model. The relationships between physical activity, sedentary behavior, and overall well-being suggest that these modifiable risk factors can be addressed such that early care and education teachers can improve their overall physical and psychological well-being, along with their life satisfaction.

Keywords: physical activity; physical well-being; psychological well-being; life satisfaction; COVID19 pandemic; early childhood educators 


\section{Introduction}

Seeking personal well-being and life satisfaction can be challenging endeavors even in the best of times. Adding a global pandemic to this set of challenges can make these pursuits even more daunting, particularly as it relates to adjusting to changes in both work and personal life. For some, the changes associated with the COVID-19 pandemic may have involved working from home, while for others it meant continuing work under very different conditions, still for others, it meant coping with the reality that their work sites had closed [1]. Early care and education (ECE) teachers serving children ages 0-5, like everyone else, had little time to make what were often significant adjustments to their lives and care for self. Moreover, early in the pandemic, the Centers for Disease Control and Prevention (CDC) categorized ECE teachers as frontline non-health care essential workers [2], which meant working under the extremely stressful and anxiety-inducing conditions that characterized the early months of the pandemic. As a result, the pandemicinduced changes experienced by ECE teachers likely influenced multiple aspects of their well-being, including physical and psychological well-being, which, by extension, likely influenced their overall life satisfaction.

Among the major concerns, public health experts raised during the pandemic were the likelihood of reduced physical activity (PA) and increased sedentary behaviors (SB) [3-5], which were more pronounced among women than men [3]. The evidence on the influence of PA and SB on physical and mental health outcomes and overall life satisfaction in the general population is well established $[4,6]$. This could be quite concerning for ECE teachers, who have been previously known to experience poor working conditions and poor physical and psychological well-being [7-10].

Despite the potentially high health risks associated with lack of PA and increased SB among ECE teachers during the pandemic, the role of PA and SB in their well-being and life satisfaction remains largely unknown. As such, the purpose of this study was to explore the associations of PA and SB with ECE teachers' well-being and life satisfaction. We explore two different models of the relationship of PA and SB with well-being and ECE teachers' life satisfaction: one with PA and SB as mediators and the other with teachers' well-being as a mediator.

\subsection{Benefit of Physical Activity for ECE Teachers}

PA is conceptualized as any bodily movement produced by skeletal muscles that require energy expenditure, which can be expressed in metabolic equivalents (METs), with more-vigorous PA entailing higher MET levels [11,12]. SB is defined as any waking behavior with an energy expenditure of fewer than 1.5 METs and includes prolonged sitting and staying in a reclining posture [13]. PA reduces the risk of cardiovascular diseases, strokes, hypertension, type 2 diabetes, osteoporosis, obesity, certain types of cancer, anxiety, and depression $[14,15]$. Conversely, SB increases the risk for those same conditions [16-18]. PA is particularly important for ECE teachers, as previous research has found that those who were more physically active were less emotionally exhausted and had less intention to leave their current position [19]. Additionally, ECE teachers serve as role models to children by helping them develop positive behaviors and attitudes toward PA [20-22]. National PA recommendations within the United States have been established to guide individuals toward a healthier lifestyle [23]. PA recommendations for healthy adults include the accumulation of $150 \mathrm{~min}$ per week of moderate-intensity aerobic activity, $75 \mathrm{~min}$ per week of vigorous-intensity aerobic activity, or an equivalent combination of moderate- and vigorous-intensity aerobic activities [23]. However, only approximately $29 \%$ of ECE teachers in the United States meet the national recommendations for PA suggesting this is an important behavior to address [24].

\subsection{The Importance of Well-Being and Life Satisfaction for Teachers in the COVID-19 Pandemic}

Well-being is a multivariate concept characterized by physical and mental health, happiness, and overall satisfaction with life [25]. We [8,9] described the concept among 
ECE teachers as "whole teacher well-being," which consists of physical, psychological, and professional well-being. Model of Whole Teacher Well-being [8] depicts this tripartite view of teacher well-being and its constituent elements. Physical well-being consists of the ability to perform activities and carry out social roles unhindered by physical limitations and experiences of bodily pain, it also includes medical status, weight in proportion to height (body mass index or BMI), sleep, and potential musculoskeletal issues [26]. Psychological well-being consists of positive emotions and feelings of happiness [27] and has numerous facets including perceptions of stress and resilience, or the ability to maintain or regain mental health despite experiencing adversity [28]. Professional well-being refers to people's feelings about their work and job based on the definition of well-being from the Centers for Disease Control and Prevention [2]. This includes indicators such as self-efficacy and job commitment $[9,29]$. Life satisfaction is an overall subjective appraisal of an individual's life experiences [30] and is strongly associated with mental health in adolescents and adults, with general health, gender, and income as contributing factors [31]. Quality of life is the confluence of the physical, psychological, and social domains of health within the context of an individual's experiences, beliefs, and perceptions [32]. Life satisfaction and related quality of life are influenced by both physical and psychological well-being [33].

Although the pandemic has been a global event, it has had a somewhat disproportionate impact on certain groups of people, especially those classified as essential workers, such as health care providers and ECE teachers. During the pandemic, many ECE teachers risked COVID-19 exposure by continuing to care for children during the outbreak. However, these benevolent acts have gone under-acknowledged or appreciated as have these valued members of the teaching workforce. Other ECE facilities closed due to safety concerns, adding additional layers of life disruption and financial stress for teachers who are low-wage earners, use public assistance, and/or are persons of color [34].

Even before the pandemic, studies indicated that ECE teachers experience a multitude of challenges to their overall well-being due to job-related physical and psychological stresses [9,24,34-38]. Pre-pandemic psychological ill-being for ECE teachers was characterized by high levels of personal stress and depressive symptoms and far surpassed national averages [34,39-42]. They also reported substantial job-related stress [43,44] and burnout [45]. These trends are important because poor teacher physical and psychological well-being are negatively associated with their professional well-being and the quality of care they provide $[9,46]$. The disruptions and upheaval of a global pandemic only served to further complicate and disrupt these trends in ECE teachers' well-being and quality of life. Studies of aspects of whole-teacher well-being examined various perspectives ranging from physical to psychological to professional, as well as their associations with teachers' life satisfaction. Kern et al. [47] used regression analysis to estimate cross-sectional associations between self-reported physical health, life satisfaction, job satisfaction, and organizational commitment in a sample of school employees, $60 \%$ of whom were teachers. They determined that staff with higher engagement (defined as vigor and dedication to work) and better relationships reported greater job satisfaction and organizational commitment. Colomeischi [48] demonstrated a significant association with life satisfaction, engagement, and emotional intelligence via multiple linear regression in a sample of teachers in Romania. Further, Kardas and colleagues [49] reported a model in which life satisfaction, along with gratitude, optimism, and hope, accounted for approximately 51\% of the variance of psychological well-being. Other studies focusing on psychological well-being reported that higher occupational stress was related to lower life satisfaction [50], and it was largely associated with psychological well-being, but not substantially related to indices of physical well-being [51]. Most of these studies suggest significant associations between various well-being indicators and life satisfaction, but the direction of, and mechanism to explain, these associations remain largely unknown. In addition, limited research evidence exists on the associations between various aspects of well-being and life satisfaction for ECE Teachers. As Hall-Kenyon and colleagues [29] note in their review of the literature related to well-being in ECE teachers, this literature is "deeply fragmented, rather narrow and 
limited." They recommended research that attends more broadly to factors of well-being, including emotional and physical health and life satisfaction.

\subsection{Physical Activity, Sedentary Behavior, and Overall Well-Being as Potential Mediators of Life Satisfaction}

PA and SB play critical roles in various aspects of one's well-being and life satisfaction. High PA and low SB are associated with higher life satisfaction and higher self-reported health [52]. PA plays a vital role in preventing numerous acute and chronic physical health conditions such as obesity, cardiovascular disease, cancer, and diabetes [23,53,54]. Moreover, PA can improve mental health and depression [55,56]. Parra-Rizo and SanchisSoler [57] found that older adults with high levels of PA had greater functional skills for activities of daily living that contribute to life satisfaction and overall well-being. Maher and colleagues [58] reported similar findings in that consistent practices of PA were positively associated with life satisfaction among middle and older adults, but not in young adults. Ginoux, et al. [59] found that regular PA improved both physical and psychological wellbeing, which included control over leisure time and relaxation. Nowak and colleagues [60] determined that the type of PA, including PA in the household, during transportation activities, and those related to occupation, had positive associations with quality of life but not with overall life satisfaction. They also found that SB during the week was positively associated with quality of life and posited that whether participants viewed PA positively or negatively might explain this association [60].

During the pandemic, studies in the population at-large indicate that decreased PA was a leading risk factor for depression [61]. Moreover, during the lockdown, increases in SB were associated with poorer mental health, and increases in PA were associated with better physical health [62]. Finally, self-isolation/quarantine was associated with higher depressive and anxiety symptoms, and individuals who changed their PA and SB during lockdown had greater physical and mental health [63]. With regard to ECE teachers specifically, a nationwide online survey on the COVID-19 impact, we reported that approximately $20 \%$ of ECE teachers experienced negative changes in their physical well-being during the pandemic [9]. Their greatest concerns related to health during the pandemic were weight gain, decreased PA, and increased SB.

PA is one of the most important and modifiable behaviors that can improve an ECE teacher's physical health (e.g., BMI), along with mental health. Lessard and colleagues [34] reported that prior to the pandemic, ECE teachers had a higher prevalence of being overweight and obese. Whitaker et al. [38] indicated that several health risks are more prevalent in ECE teachers (i.e., Head Start staff) than in the national sample (e.g., more frequent unhealthy days, three or more physical health conditions). In addition, Linnan [36] reported that they have high levels of SB and can be inactive for nearly $9 \mathrm{~h}$ in the day. Decreased PA and increased SB during the pandemic may exacerbate existing health issues and social inequities for ECE teachers. However, the information for ECE teachers is scant.

Given the reciprocal and correlational nature of the interrelationships among PA, SB, physical and psychological well-being, life satisfaction, and the influence of changes brought on by the pandemic, a greater understanding of its impact on ECE teachers and their overall life satisfaction is imperative. Thus, this study aims at investigating associations among PA, SB, well-being (i.e., physical, psychological, and professional well-being), and life satisfaction among ECE teachers during the pandemic. Based on the interrelationships identified in previous studies, we developed and tested two competing mediational models. In the first model, we hypothesized that teachers' well-being mediates the association of PA and SB with life satisfaction (see Figure 1). In our prior research [9], physical and psychological well-being played an important role in mediating the association of workplace resources and demands on professional well-being. However, based upon evidence in the literature on the role of PA and SB in one's well-being and life satisfaction [64-67], we also tested the alternative hypothesis that PA and SB mediate the association between teachers' well-being (i.e., physical, psychological, and professional well-being) and life satisfaction (see Figure 2). Our goal was to determine which of these hypothesized models 
best fit the data on ECE teachers during the early months of the pandemic (i.e., May to July in 2020).

Whole Teacher Well-Being

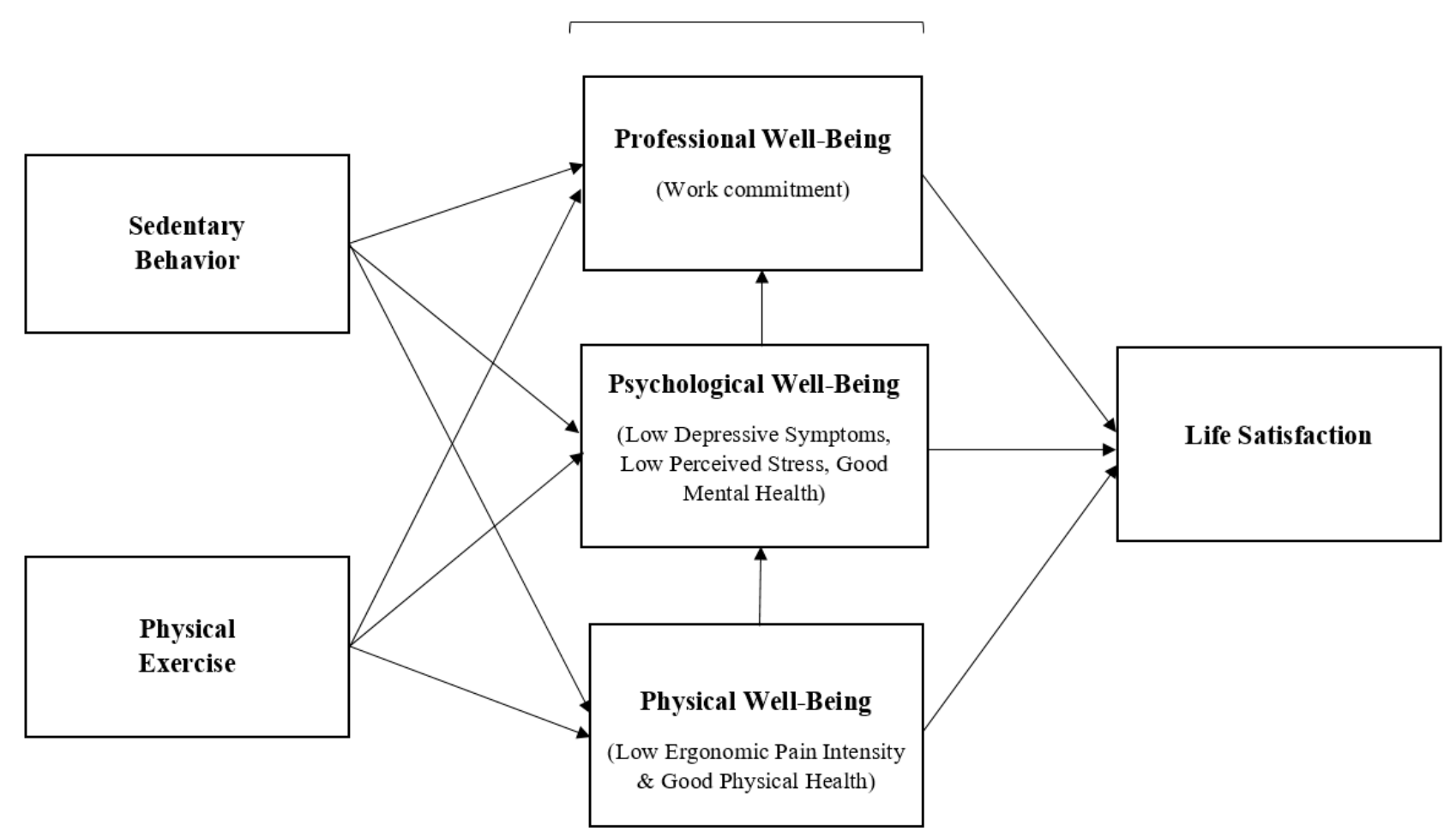

Figure 1. Well-being Mediation Model of Physical Activity and Life Satisfaction.

\section{Whole Teacher Well-Being}

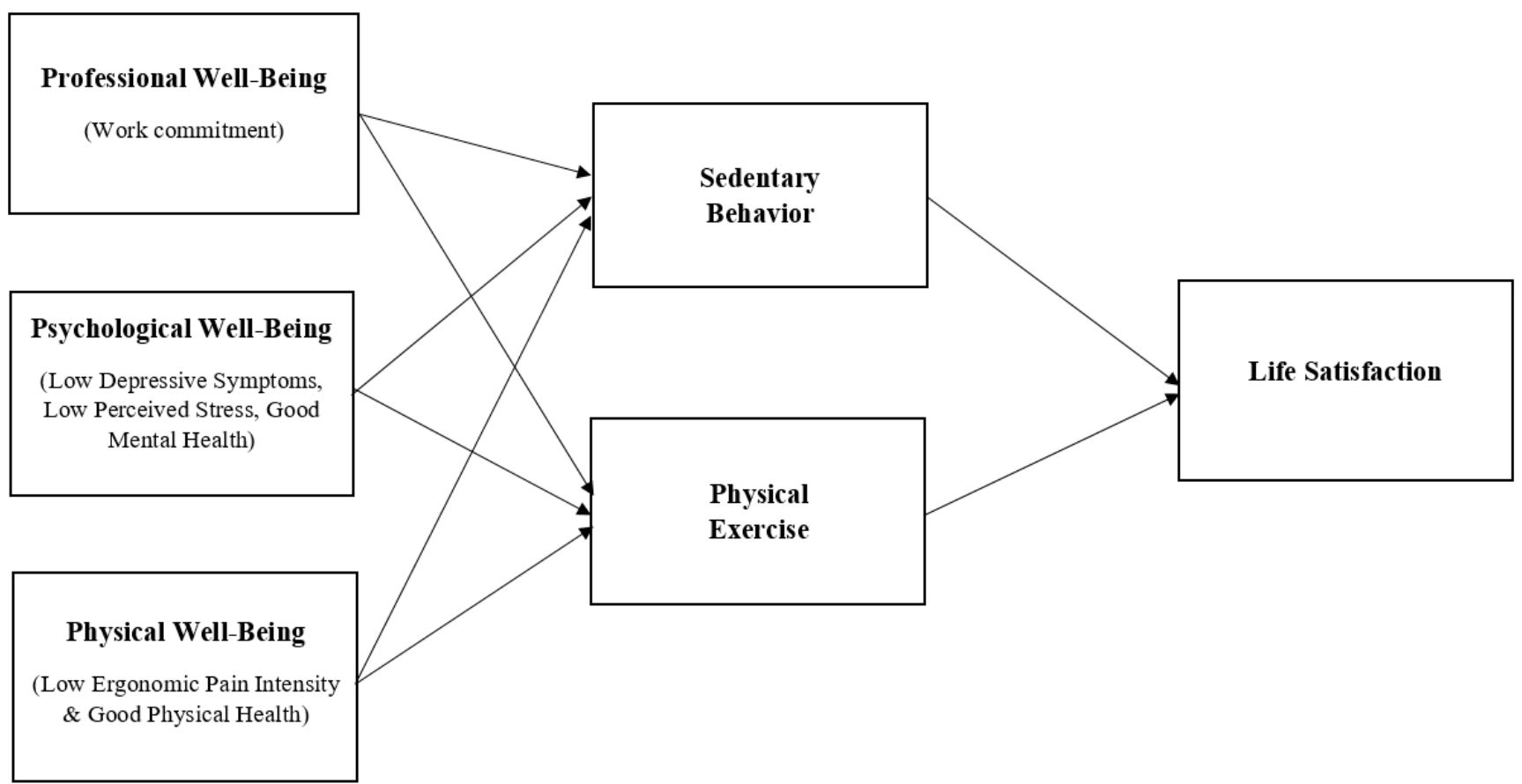

Figure 2. Physical Activity Mediation Model of Well-being and Life Satisfaction. 


\section{Materials and Methods}

\subsection{Participants and Setting}

A total of 1434 ECE teachers serving children aged between 0 and 5 (including Kindergarten) in 46 states in the United States completed the online survey from May to July in 2020, which is an early phase of the COVID-19 pandemic. The average age of the participants was 42 (Range $=17$ to $80, S D=12.03$ ). The majority of teachers in the sample were women $(98.3 \%)$. The participating teachers had diverse racial/ethnic and educational backgrounds. The overall racial/ethnic composition of the sample is similar to the population of ECE teachers nationally [68], with a somewhat higher percentage of Hispanic ECE teachers. The sample includes $60 \%$ White, 20\% Hispanic, 14\% Black, 4\% American Indian or Alaska Native, 3\% biracial, and 1\% Asian. Of the participating teachers, 53\% held a bachelor's degree or higher, followed by some college but no degree $(20 \%)$, associate degree $(19 \%)$, and high school diploma or graduate equivalency $(5 \%)$. The majority of teachers in the sample were fully paid ( $83 \%)$, but $12 \%$ were only partially paid, and $5 \%$ were not paid at all. Among those who were paid, the annual salary for more than half of the participating teachers was below USD 30,000. Furthermore, $15 \%$ of teachers were on welfare and received some form of public support such as Medicaid, food stamps, or childcare subsidies.

Participating teachers worked in Head Start programs (43\%), childcare centers (34\%), public schools $(14 \%)$, family childcare homes $(6 \%)$, and private schools $(3 \%)$. They served infants and toddlers $(24 \%)$, preschool or pre-K $(38 \%)$, Kindergarten $(6 \%)$, and children in multiage groups (31\%). Of the 1234 ECE teachers in the sample, approximately $27 \%$ reported they were teaching in person, 37\% were teaching online, and the remaining $36 \%$ were not teaching due to their centers being closed as a result of the pandemic.

\subsection{Research Procedure and Analysis}

Our interdisciplinary research team developed a 73-item online survey. It began with a description of the study and confidentiality statement and informed consent was acquired by the participants deciding to complete the survey. The first part of the survey collected information related to demographics, geographic location, socioeconomics, education, and work-related information. The survey collected information on physical well-being including PA, SB, psychological well-being, professional well-being, job demands, and life satisfaction during the pandemic. Portions of the survey consisted of previously validated scales and many items included text boxes for open-ended responses. More detailed descriptions and the psychometric properties of each measure are organized in Table 1.

Table 1. Measures Used in the Current Study.

\begin{tabular}{|c|c|c|c|c|}
\hline & $\begin{array}{c}\text { Study } \\
\text { Variables }\end{array}$ & Instruments & Instrument Characteristics & Psychometric Properties \\
\hline \multirow{3}{*}{$\begin{array}{c}\text { Physical } \\
\text { Well-being }\end{array}$} & $\begin{array}{c}\text { Overall } \\
\text { Health Status }\end{array}$ & $\begin{array}{l}\text { SF-12 Health Survey } \\
\text { Standard, Version } 1 \text { [69] }\end{array}$ & $\begin{array}{l}\text { The SF-12 is a shortened version of the } \\
\text { SF-36 with questions in } 8 \text { domains. } \\
\text { The survey includes a Physical } \\
\text { Component Score (PCS) subscale. }\end{array}$ & $\begin{array}{l}\text { Reliability } \alpha=0.78-0.85[70] \\
\text { Cronbach's } \alpha=0.83[71]\end{array}$ \\
\hline & $\begin{array}{c}\text { Physical } \\
\text { Activity (PA) }\end{array}$ & $\begin{array}{l}\text { International Physical } \\
\text { Activity Questionnaire } \\
\text { (IPAQ) Short Last } \\
7 \text { Days format [72] }\end{array}$ & $\begin{array}{l}\text { 7-item self-administered questionnaire } \\
\text { providing an estimate of physical } \\
\text { activity and sedentary behavior over } \\
\text { the last seven days. Used with adults } \\
\text { aged } 15-69 \text { years old. }\end{array}$ & $\begin{array}{c}\text { Reliability } \alpha=0.80 \\
\text { Criterion Validity } \\
\text { Spearman's } \rho=0.30[73]\end{array}$ \\
\hline & $\begin{array}{l}\text { Days/hours } \\
\text { spent on PA }\end{array}$ & Questionnaire & $\begin{array}{l}\text { Ascertains days and hours spent in } \\
\text { moderate to vigorous physical } \\
\text { activities (150 min/week used as } \\
\text { threshold) on a weekly basis }\end{array}$ & \\
\hline
\end{tabular}


Table 1. Cont.

\begin{tabular}{|c|c|c|c|c|}
\hline & $\begin{array}{c}\text { Study } \\
\text { Variables }\end{array}$ & Instruments & Instrument Characteristics & Psychometric Properties \\
\hline & $\begin{array}{l}\text { SB/Hours of } \\
\text { Sitting }\end{array}$ & Questionnaire & $\begin{array}{l}\text { Time spent on sedentary activities in } \\
\text { past four weeks (none of the time, a } \\
\text { little of the time, some of the time, or a } \\
\text { good bit of the time) }\end{array}$ & \\
\hline & $\begin{array}{l}\text { Ergonomic } \\
\text { Pain }\end{array}$ & $\begin{array}{l}\text { Modified Work-Related } \\
\text { Musculoskeletal } \\
\text { Disorders scale [74] }\end{array}$ & $\begin{array}{l}\text { Five binary items asking about } \\
\text { experienced pain in neck, back, } \\
\text { shoulder, knee, and other. Total score } \\
\text { combined all items. }\end{array}$ & $\begin{array}{l}\text { Cronbach's } \alpha=0.90 \\
\text { Test-retest reliability } \\
\text { Pearson } r>0.75[74]\end{array}$ \\
\hline \multirow{3}{*}{$\begin{array}{l}\text { Psychological } \\
\text { Well-being }\end{array}$} & $\begin{array}{c}\text { Life } \\
\text { Satisfaction }\end{array}$ & $\begin{array}{l}\text { Satisfaction with Life } \\
\text { Scale [75] }\end{array}$ & $\begin{array}{l}\text { Scale consists of } 5 \text { items measuring } \\
\text { global cognitive judgments of a } \\
\text { person's life satisfaction ranging from } \\
1 \text { (strongly disagree) to } 7 \text { (strongly } \\
\text { disagree). }\end{array}$ & $\begin{array}{l}\text { Test-retest correlation } \\
\text { coefficient } \alpha=0.82 \\
\text { coefficient } \alpha=0.87[75]\end{array}$ \\
\hline & $\begin{array}{l}\text { Depressive } \\
\text { Symptoms }\end{array}$ & $\begin{array}{l}\text { Center for } \\
\text { Epidemiologic Studies } \\
\text { of Depression Short } \\
\text { Form (CES-D-10) [76] }\end{array}$ & $\begin{array}{l}\text { 10-item screening test on frequency of } \\
\text { symptoms in the past week on a scale } \\
\text { of } 0 \text { (not at all or less than } 1 \text { day) to } 3 \\
\text { (5-7 days). Scores equal to or above } 10 \\
\text { are considered to indicate a screen of } \\
\text { depression }\end{array}$ & $\begin{array}{l}\text { CES-D-10; Cronbach } \\
\alpha=0.65-0.91[77,78]\end{array}$ \\
\hline & Stress & $\begin{array}{l}\text { The Perceived Stress } \\
\text { Scale (PSS) [79] }\end{array}$ & $\begin{array}{c}\text { Questions about current levels of } \\
\text { experienced stress ranging from } 1 \\
\text { (rarely/never) to } 5 \text { (very often). The } \\
\text { PSS is a predictor of depressive and } \\
\text { physical symptomatology (Cohen } \\
\text { et al., 1983) }\end{array}$ & $\begin{array}{c}\text { PSS; Cronbach } \alpha=0.84 \\
\text { test-retest reliability } \\
\text { Pearson } r=0.85[79]\end{array}$ \\
\hline $\begin{array}{l}\text { Professional } \\
\text { Well-being }\end{array}$ & $\begin{array}{c}\text { Work } \\
\text { Commitment }\end{array}$ & $\begin{array}{l}\text { Early Childhood Job } \\
\text { Satisfaction Survey } \\
\quad \text { (ECJSS) [80] }\end{array}$ & $\begin{array}{l}\text { Ten questions (true/false) exploring } \\
\text { factors related to work satisfaction } \\
\text { and commitment. Scores range from } 0 \\
\text { (low) to } 10 \text { (high) levels of work } \\
\text { commitment. }\end{array}$ & $\begin{array}{l}\text { Overall consistency for } \\
\text { ECJSS: } \alpha=0.89[81] \\
\text { Internal consistency } \\
\text { reliability } \alpha=0.80[82]\end{array}$ \\
\hline
\end{tabular}

\subsubsection{Measures of Physical Well-Being}

Elements of the survey that collected information on teacher's physical well-being included measures of general health condition, BMI, PA, SB, sleep, food security, and ergonomic pain. We measured PA and SB using elements of the International Physical Activity Questionnaire (IPAQ) Short Last 7 Days Self-administered format [72] and the SF-12 Health Survey Standard, Version 1 [69]. Hours of sleep were collected using a scale from 4 or less, 5, 6, 7, 8, 9, or 10 or more hours. Food security (including nutrition and eating habits) was measured using a modified version of The United States Department of Agriculture Short Form of the Food Security Survey Module [83]. Ergonomic pain was assessed using the modified version of the Work-Related Musculoskeletal Disorders Scale (WMDS) [74].

To measure PA and SB, direct survey questions asked about how many days and hours teachers spent in moderate to vigorous physical activities, and how much time they spent sitting on a weekday. The IPAQ is a frequently used measure of PA, with extensive reliability and validity studies, that spans 12 countries [72,73]. The short format captures $\mathrm{PA}$ in the last seven days with questions specific to vigorous PA and questions specific to moderate PA, along with how many days, as well as how many hours, in a week ECE teachers spent in each. The Federal Physical Activity Guidelines (PAG) and the ACSM diverge on their recommendations of vigorous PA each week. Federal PAG guidelines recommend $75 \mathrm{~min} /$ week and ACSM suggests $60 \mathrm{~min} /$ week, however, they both agree on $150 \mathrm{~min} /$ week of moderate PA. As such, we modified the survey to ask about moderate to vigorous PA, using $150 \mathrm{~min} /$ week as our threshold. "Insufficiently active" is defined 
by the U.S. Department of Health and Human Services Physical Activity Guidelines for Americans [84] as "doing some moderate or vigorous-intensity physical activity but less than 150 min a week." In this study, we equate insufficiently active with being sedentary or engaging in prolonged bouts of sitting and we collected information on hours of sitting during a weekday.

\subsubsection{Measures of Physical Activity and Sedentary Behavior}

The research team developed evidence-informed guidelines for assessing the frequency of PA and SB. We used $150 \mathrm{~min}$ per week (or $30 \mathrm{~min}$ five days a week) of moderate to vigorous PA every week as the threshold for meeting PA guidelines [84-86]. The available evidence for thresholds of both PA and SB is sparse. Although studies encourage the population to "move more and sit less" [85] and to break up prolonged sitting times with PA [86], few provide specific amounts of time. In a nationally representative survey of US adults over nine years, Du and colleagues [85] determined that adults sit an average of six hours per day. Only one study by Tremblay and colleagues [87] offers a specific metric, recommending "for adults aged 18 to 64 years and adults aged 65 years and older we recommend limiting sedentary time to $8 \mathrm{~h}$ or less," yet they acknowledge that these are "strong recommendations based on low-to-very-low-quality evidence." For survey data related to sitting times, if respondents provided exact estimates, we used that information in our data set. If they used a descriptive in the provided text boxes, such as "half the workday", "some", or "a fair amount", we used six hours as a median [85]. We used eight hours or more if respondents used phrases such as "too much" or "almost all day," or the equivalent per Tremblay et al. [87]. If responses were for a total week instead of a day (since the IPAQ asks for both), we used multiples of the preceding numbers (e.g., $30 \mathrm{~h}$ per week or six hours $\times 5$ weekdays would be our average, and $40 \mathrm{~h}$ or above would be "too much").

\subsubsection{Measures of Psychological Well-Being}

Teachers' psychological well-being was operationalized via ECE teachers' perceptions of life satisfaction, depressive symptoms, stress, resiliency, and secondary trauma. Life satisfaction was gauged using the Satisfaction with Life Scale [75]. We assessed teacher depressive symptoms via the 10-item Center for Epidemiologic Studies of Depression Short Form (CES-D-10) [88]. Stress was measured using The Perceived Stress Scale (PSS) [79] and resiliency was measured using the Brief Resilience Scale [89]. Teachers' secondary trauma was assessed using one of the subscales of the Professional Quality of Life Scale [90]. Finally, the SF-12 Health Survey Standard, Version 1 [69], mentioned previously as a measure of physical health also produces a mental health sub-scale. We calculated a simple, raw score for each of the SF-12 physical and mental health sub-scales. To preserve intact cases, sporadic missing data on the various items of the SF-12 were imputed via item correlation substitution (ICS). In ICS, a missing value for one item is replaced by the value of the measured item with which is it most highly correlated. Such a method of imputation is effective in scales with few response options and a low percentage of missing values [91]. In the case of the SF-12, this approach was robust from 2 but less than 3 missing values per case, which constituted $99 \%$ of all cases. Cases that had more than 3 missing values were ignored. More discussion of the handling of missing data for other study variables is described in more detail below in the data analysis section.

\subsubsection{Measures of Professional Well-Being and Job Demands}

Professional well-being was assessed via two constructs: work commitment and intent to leave. Work commitment was measured using the Early Childhood Job Satisfaction Survey (ECJSS) [80]. Intent to leave the field/profession was measured via three survey items. Measures of job demands were assessed using The Job Content Questionnaire (JCQ) [92], which consists of three subscales: physical job demands, skill discretion, and decision authority. 
After receiving Institutional Research Board (IRB) approval, we recruited ECE teachers to participate in the survey via various social media platforms (e.g., Facebook, Twitter) as well as e-mails to early childhood organizations, agencies, programs, and schools. As an incentive, we offered survey respondents the chance to win one of 120 USD 50 gift cards in a random drawing.

\subsection{Data Analysis}

To test our hypothesized models, we employed a structural equation modeling (SEM) approach via AMOS 25.0 using maximum likelihood estimation. Additionally, to adjust for any non-normality in our key variables, we generated bootstrapped estimates, standard errors, and bias-corrected confidence intervals using the AMOS program with a resampling size of 1000. In testing our model, we considered the following covariates as controls: (a) whether the teacher earned a bachelor's degree or not, (b) teacher income, and (c) center status/teaching modality (open center, online/virtual, or closed center) at the time of the study. The age and ethnicity of teachers were not included as controls for reasons of parsimony; they exhibited no relationship to the endogenous variables in the models and had negligible impact on model fit. The effective sample size for our analysis was 1234 teachers.

Teachers in the sample who were missing scores on any one of the variables in the analysis (with exception of the SF-12) were removed prior to analysis (i.e., the values were not imputed). Variables in the dataset, including the SF-12, exhibited a general item non-response pattern [93]. This missing data pattern manifests as gaps in item response that appear to be randomly dispersed throughout the dataset (i.e., MCAR). In this case, we endeavored to determine whether or not there were significant differences between teachers who were missing scores for our measured variables and those who were not-in other words, could the data be assumed to be missing completely at random (MCAR) which is needed to justify listwise deletion. To test this assumption, we conducted a series of Bonferroni corrected t-tests and chi-squared tests of independence between teachers who had values and those for whom they were missing for each variable. We found no significant differences between the groups with respect to our measured variables, and thus, listwise deletion was a justifiable missing data-handling approach (Enders, 2010). The reason for singling out the SF-12 specifically for imputation was due to random missingness patterns across all of the cases, which were highly unique across its 12 items. Of the teachers, $86 \%$ responded to all items on the SF-12, but the other cases were missing in many differing patterns, which resulted in a substantial number of lost cases when the missingness of the other study variables was taken into account. Once ICS was conducted on the SF-12, the number of lost cases dropped from over 500 down to just 200.

SEM construction began by first conducting confirmatory factor analyses (CFAs) of all candidate-latent measures of well-being. Our criteria for including latent measures in our final SEM was based upon factor loadings given that three-item (or less) CFAs are just- or under-identified and, therefore, provide no fit statistics. Factor loadings for all variables included in the measurement model were well above 0.5 . This initial analysis yielded latent measures for use in the overall structural model of psychological well-being and physical well-being. Once CFAs were conducted and our latent measures were established, our overall modeling approach was primarily driven by our conceptual framework and prior research, but also included an empirical component for the purposes of testing direct paths as well as refining and settling on a final model.

We first tested our hypothesized model with all possible paths entered between these constructs. From here, we employed a model trimming approach [94] based upon the results of the saturated model where we eliminated non-significant paths step-by-step and examined our path estimates, as well as absolute and incremental fit statistics (see the Results for a more detailed discussion) retaining those paths that were theoretically justified and supported by empirical data. Though our model was hypothesized as fully mediational, at this stage, we tested direct paths from our exogenous variables to the endogenous 
variables in each mediational model. We retained those direct paths that were significant and improved model fit. Finally, we entered the aforementioned control variables (earned bachelor's degree, teacher income, teaching modality) and tested their direct relationships to each of the outcome variables in our model. We retained those that improved model fit or were otherwise theoretically important, whether or not they were significant. Finally, as a final test of our framework, we tested the fit of our main alternative model against our hypothesized model specification. We were looking for a good-fitting model that also represented the more likely mediational reality of the relationship between physical activity, sedentary behavior, our three dimensions of well-being, and life satisfaction.

In assessing fit for the SEM analysis, we chose both measures of absolute (e.g., chisquare, RMSEA, pclose) and incremental fit (e.g., CFI, TLI). Established guidelines suggest that TLI and CFI statistics of 0.95 or higher indicate a good model fit; similarly, an RMSEA of less than 0.05 [95]. Furthermore, retaining the null of the pclose test, a test of whether or not RMSEA is "close-fitting" (i.e., RMSEA equal to 0.05), also indicates a good model fit. A non-significant chi-square value indicates a good overall fit; however, because it is well known to be sensitive to sample size (typically leading to a rejected null), we relied more heavily on our other chosen indices in assessing model fit. All variables in our SEM models have been standardized for ease of interpretation as effect sizes.

\section{Results}

Table 2 presents some basic descriptive statistics on our study sample and variables. Survey respondents produced a range of information with regard to income, educational level, and school status, along with metrics of overall life satisfaction, which included physical, psychological, and professional well-being. Nearly half of the ECE teachers reported an annual income between USD 20,000 and 30,000 (27.4\%) and USD 30,000 and $40,000(22.4 \%)$, and nearly equal percentages occupied the low and high ends of the range, with 5.8\% making below USD 10,000 and 5.5\% making above USD 70,000. Respondents had a mean life satisfaction score of 24.7 , reflecting overall "slight satisfaction."

The aggregate score of the full sample on the SF- 12 physical health subscale was 16.47 (lowest possible score of 6 and highest of 20) [96] (p. 383), and their overall intensity of reported ergonomic pain (with a maximum of 20) was 3.50. They spent on average $6.5 \mathrm{~h}$ a day being sedentary, with just over a third (39\%) meeting the recommended $150 \mathrm{~min}$ of moderate-intensity PA per week. Mean BMI was 31.5, which classifies as obese, with $0.8 \%$ of participants classifying as underweight, $22.0 \%$ were normal BMI, $27.0 \%$ were in the overweight category, and 50.2\% in the obese category [97]. The range of BMIs was from 12.73 to 80.69 , indicating that, if height and weight were accurately self-reported, some respondents weighed over 500 pounds. From a psychological well-being standpoint, survey respondents had a mean score of 16.6 on the SF-12 psychological health subscale (MCS) (lowest possible score of 6 and highest of 27), their mean perceived stress score was 25.77, indicating the upper end of "moderate stress" (Cohen et al., 1983) and their mean depressive symptoms were 8.47 (a score of 10 or higher indicates depression) (Eaton et al., 2004). The teachers' mean work commitment score was $8.52(0=$ low work commitment, $10=$ high work commitment) [80].

Finally, to provide a sense of the underlying relationships between our key variables prior to the SEM analysis, zero-order correlations among key variables are presented in Table 3. Of note are the moderate relationships between our well-being measures as well as these well-being measures and our outcome life-satisfaction. Additionally notable, is the lack of a significant relationship between PA (more than $150 \mathrm{~h}$ of moderate exercise per week) and SB (number of sedentary hours per day), $r=02, p=0.92$ ). 
Table 2. Descriptive Statistics for Study Variables $(n=1234)$.

\begin{tabular}{|c|c|}
\hline Categories & Percentage OR Mean (Range OR SD) \\
\hline \multicolumn{2}{|l|}{ Teacher Characteristics } \\
\hline$\overline{\text { Held Bachelor's Degree }}$ & $0.55(0.49)$ \\
\hline Income & $3.80(1.70)$ \\
\hline USD $10 \mathrm{k}$ or less & $5.8 \%$ \\
\hline USD 10,001 to USD $20 \mathrm{k}$ & $15.9 \%$ \\
\hline USD 20,001 to USD $30 \mathrm{k}$ & $27.4 \%$ \\
\hline USD 30,001 to USD $40 \mathrm{k}$ & $22.4 \%$ \\
\hline USD 40,001 to USD $50 \mathrm{k}$ & $14.4 \%$ \\
\hline USD 50,001 to USD $60 \mathrm{k}$ & $5.7 \%$ \\
\hline USD 60,001 to USD $70 \mathrm{k}$ & $3.0 \%$ \\
\hline USD $70 \mathrm{k}$ and up & $5.5 \%$ \\
\hline Teacher School Open During Pandemic & $0.28(0.45)$ \\
\hline Teacher School Online Learning During Pandemic & $0.27(0.44)$ \\
\hline Teacher School Closed During Pandemic & $0.45(0.49)$ \\
\hline Life Satisfaction & $24.74(5-35)$ \\
\hline \multicolumn{2}{|l|}{ Psychological Well-being } \\
\hline Perceived Stress & $25.77(10-47)$ \\
\hline Depressive Symptoms & $8.47(0-30)$ \\
\hline Mental Health Scale (MCS, SF-12) & $16.64(2-23)$ \\
\hline \multicolumn{2}{|l|}{ Professional Well-being } \\
\hline Work Commitment & $8.52(1-10)$ \\
\hline \multicolumn{2}{|l|}{ Physical Well-being } \\
\hline Ergonomic Pain Intensity ${ }^{a}$ & $3.50(0-19)$ \\
\hline Physical Health Scale (PCS, SF-12) & $16.47(4-20)$ \\
\hline \multicolumn{2}{|l|}{ Physical Activity } \\
\hline Sedentary hours per day & $6.52(3.41)$ \\
\hline More than 150 min of moderate physical activity per week & $0.39(0.49)$ \\
\hline
\end{tabular}

Note. ${ }^{\text {a }}$ Is an indicator of the product of both number of affected areas (max of 5 areas) and severity of pain (from $0=$ no pain to $4=$ unbearable pain), for a max range of 20 .

Table 3. Zero-Order Correlations for Study Variables.

\begin{tabular}{|c|c|c|c|c|c|c|c|c|c|c|c|c|}
\hline Measure & 1 & 2 & 3 & 4 & 5 & 6 & 7 & 8 & 9 & 10 & 11 & 12 \\
\hline $\begin{array}{l}\text { 1. Life } \\
\text { satisfaction }\end{array}$ & ----- & & & & & & & & & & & \\
\hline $\begin{array}{l}\text { 2. Mental health } \\
\text { (MCS) }\end{array}$ & $0.44^{* *}$ & ---- & & & & & & & & & & \\
\hline $\begin{array}{l}\text { 3. Low } \\
\text { depressive } \\
\text { symptoms }\end{array}$ & $0.52^{* *}$ & $0.62 * *$ & ----- & & & & & & & & & \\
\hline $\begin{array}{l}\text { 4. Low personal } \\
\text { stress }\end{array}$ & $0.51^{* *}$ & $0.63^{* *}$ & $0.71^{* *}$ & ----- & & & & & & & & \\
\hline 5. Physical & $0.29^{* *}$ & $0.38^{* *}$ & $0.33^{* *}$ & $0.30^{* *}$ & ----- & & & & & & & \\
\hline $\begin{array}{l}\text { 6. Ergonomic } \\
\text { pain intensity }\end{array}$ & -0.20 & -0.29 & -0.28 & -0.23 & -0.51 & ----- & & & & & & \\
\hline $\begin{array}{l}\text { 7. Work } \\
\text { commitment }\end{array}$ & $0.26^{* *}$ & $0.21^{* *}$ & $0.25^{* *}$ & $0.27^{* *}$ & -0.20 & -0.17 & ----- & & & & & \\
\hline $\begin{array}{l}\text { 8. \# Sedentary } \\
\text { hours/day }\end{array}$ & $-0.04 *$ & -0.12 & $-\underset{* *}{0.07}$ & $-0.05 *$ & -0.04 & $0.09 * *$ & 0.02 & ----- & & & & \\
\hline $\begin{array}{l}\text { 9. }>150 \mathrm{~min} \\
\text { mod. } \\
\text { Exercise/wk }\end{array}$ & $0.10^{* *}$ & $0.13^{* *}$ & $0.08^{* *}$ & $0.07^{* *}$ & $0.15^{*}$ & -0.07 & 0.00 & 0.02 & ----- & & & \\
\hline 10. Income & $0.09 * *$ & 0.02 & 0.03 & 0.03 & $0.14^{* *}$ & 0.01 & 0.03 & -0.07 & $0.07^{* *}$ & ----- & & \\
\hline $\begin{array}{l}\text { 11. Bachelor's } \\
\text { degree }\end{array}$ & $0.08^{* *}$ & 0.02 & 0.01 & 0.02 & $0.07^{* *}$ & 0.00 & $-0.05^{*}$ & $0.11^{* *}$ & $0.06^{*}$ & $0.42 * *$ & ----- & \\
\hline 12. Open school & $-0.06^{*}$ & $0.11^{* *}$ & -0.03 & -0.04 & $0.09^{* *}$ & $0.07^{* *}$ & -0.06 & -0.10 & -0.02 & -0.15 & -0.25 & ---- \\
\hline $\begin{array}{l}\text { 13. Virtual } \\
\text { school }\end{array}$ & 0.04 & -0.01 & -0.02 & 0.02 & $0.04 *$ & -0.02 & 0.00 & $0.08 * *$ & -0.01 & $0.17^{* *}$ & $0.22 * *$ & -0.40 \\
\hline
\end{tabular}

${ }^{* *} p<0.01, * p<0.05$. Note. Non-parametric correlational analysis used for income, bachelor's degree, 150 min exercise, online and virtual school. Ergonomic pain intensity is summed products of each point of pain and reported severity. 


\section{Empirical Tests of Competing Mediation Models}

The overarching inquiry of this study was whether PA or aspects of well-being serve as the better mediator of the associations between PA and ECE teachers' life satisfaction. Our final well-being mediation model is displayed in Figure 3. The empirical test of this mediation model revealed very good, close model fit, $\chi^{2}(54)=188.53, p<0.001$, $\mathrm{CFI}=0.963, \mathrm{TLI}=0.946, \mathrm{RMSEA}=0.045,90 \% \mathrm{CI}(0.038,0.052)$, pclose $=0.877$ (ns), according to established SEM guidelines [98]. Overall, these findings suggest that the latent and observed measures and the relationships between them in our recursive, fitted model matched the covariance structure of the data well. Our final model explained approximately $40 \%$ of the variance in life satisfaction, $26 \%$ of the variance in psychological well-being, and approximately $10 \%$ of the variance in professional well-being.

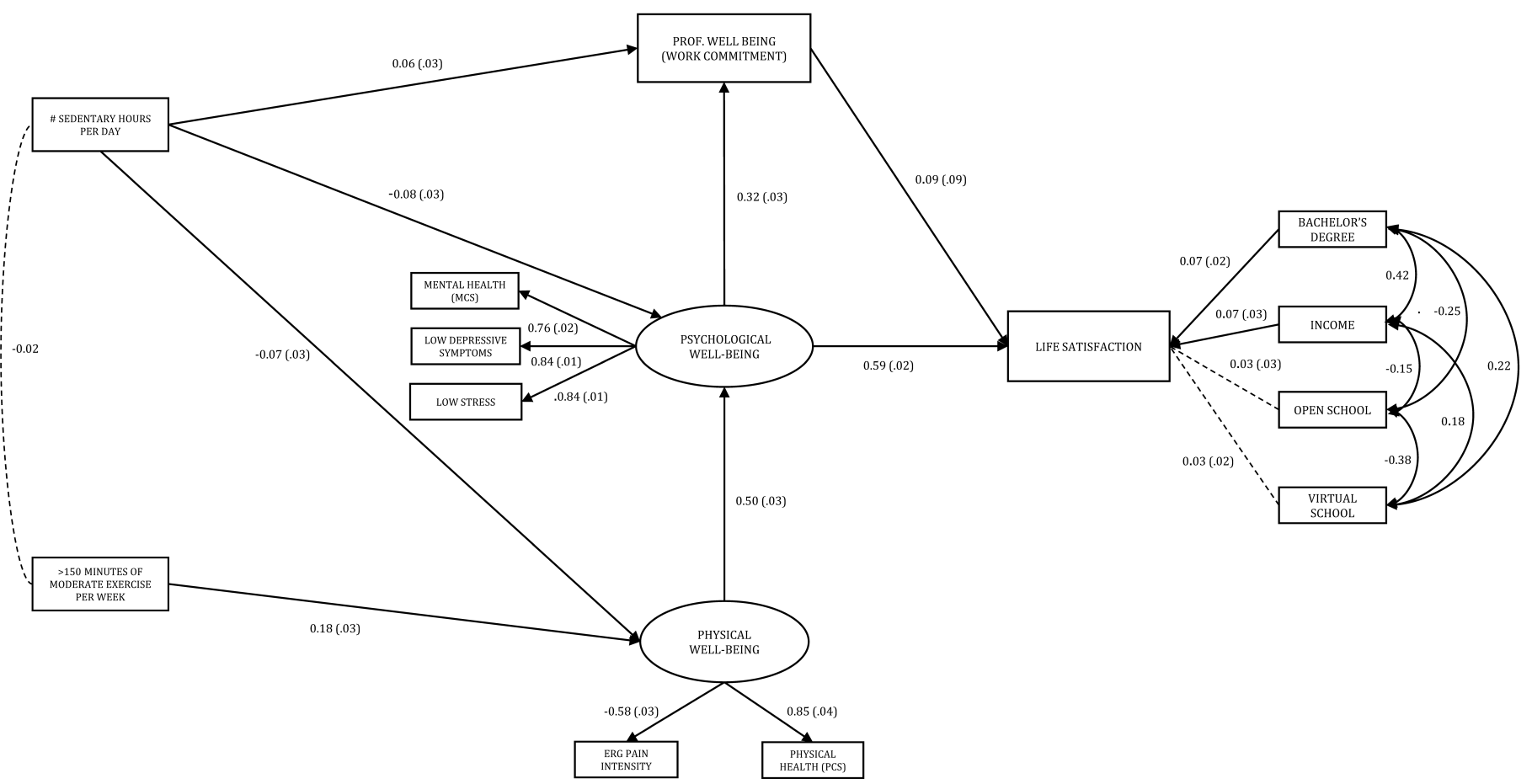

Figure 3. Empirical Test of Well-Being Mediation Model. Note. Bootstrapped standardized estimates and standard errors reported (resampling size $=1000$ ), standard errors in parentheses. The regression weights for PCS and low stress were constrained to 1 for analysis. All paths significant $p<0.01$ except sedentary hours per day to professional well-being, $p<0.05$. Dotted paths / covariances non-significant. Fit statistics: $\chi^{2}=188.53, \mathrm{df}=54, p<0.001, \mathrm{TLI}=0.946, \mathrm{CFI}=0.963$, and RMSEA $=0.045,90 \%$ CI [0.038-0.052], pclose $=0.877$.

With respect to the well-being mediation model, there were several key findings. First is that the three aspects of teacher well-being (physical, psychological, and professional) mediated the relationship between PA, SB, and life satisfaction. There were two main indirect paths from PA (i.e., more than $150 \mathrm{~min}$ of moderate PA per week) to life satisfaction. The weaker of the two was through all three well-being measures (physical, psychological, and professional well-being; indirect $\beta=0.002$ ). The stronger of the two flowed through only physical and psychological well-being; indirect $\beta=0.053$. The total indirect effects of PA on life satisfaction were significant, $\beta=0.055, S E=0.011, p<0.001,95 \%$ CI $(0.038,0.079)$. The total indirect effects of SB on life satisfaction through physical, psychological, and professional well-being were also statistically significant; indirect $\beta=-0.065, S E=0.019$, $p<0.01,95 \%$ CI $(-0.101,-0.029)$.

Of note was the indirect effect of physical well-being on life satisfaction through psychological well-being, which was over three-tenths of a standard deviation, $\beta=0.307$, $S E=0.024, p<0.001,95 \%$ CI $(0.262,0.354)$, as well as the direct effect of psychological 
well-being on life satisfaction, which was well over a half a standard deviation, $\beta=0.589$, $S E=0.025, p<0.001,95 \%$ CI $(0.540,0.637)$. Not surprisingly, more than $150 \mathrm{~min}$ a week of moderate PA was directly and positively associated with physical well-being, $\beta=0.178$, $S E=0.038, p<0.001,95 \%$ CI $(0.126,0.243)$, and sedentary behavior was negatively associated with physical, $\beta=-0.068, S E=0.032, p<0.05,95 \% \mathrm{CI}(-0.134,-0.009)$, and psychological well-being, $\beta=-0.080, S E=0.029, p<0.01,95 \%$ CI $(-0.136,-0.022)$, respectively.

Finally, our empirical test of the PA mediation model is displayed in Figure 4. This model had good, close fit, but was slightly inferior in fit to the well-being mediation model, $\chi^{2}=195.47, \mathrm{df}=55, p<0.001, \mathrm{TLI}=0.945, \mathrm{CFI}=0.961$, and $\mathrm{RMSEA}=0.046,90 \% \mathrm{CI}$ [0.039-0.053], pclose $=0.851$. Furthermore, an empirical test of a potential PA mediation model revealed, in fact, no mediation, due to non-statistically significant paths from SB to life satisfaction and from PA to life satisfaction, direct $\beta=-0.018, S E=0.025, p=0.481$, $95 \% \mathrm{CI}(-0.071,0.030)$ for SB; $\beta=0.037, \mathrm{SE}=0.022, p=0.116,95 \% \mathrm{CI}(-0.009,0.075)$ for PA respectively.

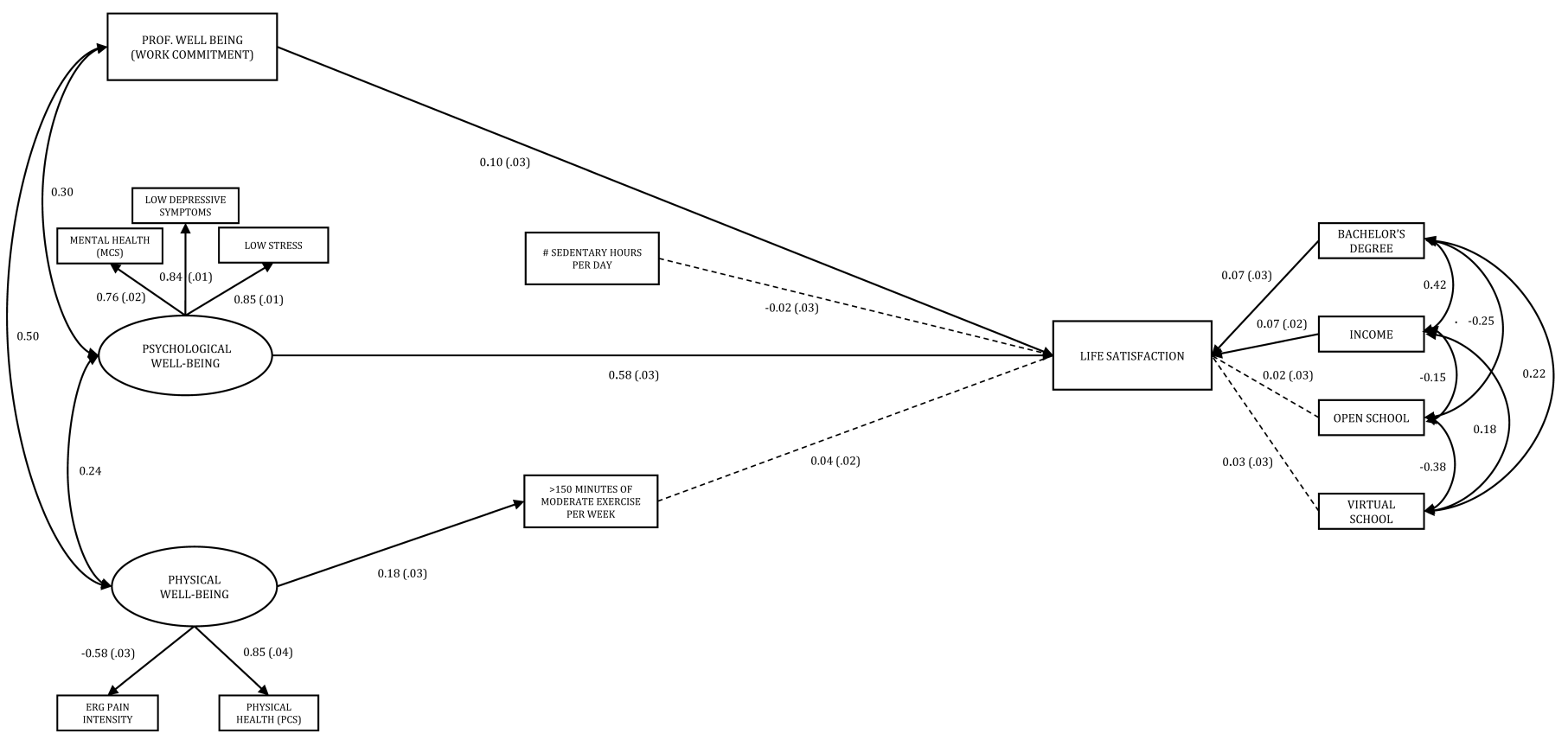

Figure 4. Empirical Test of Physical Activity Mediation Model. Note. Bootstrapped standardized estimates and standard errors reported (resampling size $=1000$ ), standard errors in parentheses. The regression weights of PCS and low depressive symptoms were constrained to 1 for analysis. All paths significant $p<0.01$. Dotted paths/covariances non-significant. Fit statistics: $\chi^{2}=195.47, \mathrm{df}=55, p<0.001, \mathrm{TLI}=0.945, \mathrm{CFI}=0.961$, and RMSEA $=0.046,90 \%$ CI [0.039-0.053], pclose $=0.851$.

\section{Discussion}

The present study investigated the associations of PA and SB with ECE teachers' wellbeing and life satisfaction during the early phase of the COVID-19 pandemic in 2020. We explored two mechanisms through which PA, SB, and well-being are associated with ECE teachers' life satisfaction: one with PA and $\mathrm{SB}$ as mediators and the other with teachers' well-being as a mediator. The overall conclusion of this analysis is that, while both models fit well, the model where teacher well-being was the mediator was superior. This is not only because it fit slightly better, but because it represented a mediation, whereas the model of PA was not technically a mediation, having non-significant paths from well-being to life satisfaction. We unpack these results more below, beginning with the well-being mediation model.

In addition to informing our model development, data from the survey produced a wealth of information about various aspects of ECE teachers' well-being, their levels of 
PA, SB, and overall life satisfaction during the COVID-19 pandemic. Respondents had a mean life satisfaction score that qualified as slight satisfaction, they experienced moderate stress, and, collectively, were approaching the threshold for depression yet still reflected moderate-to-high work commitment. Over half of the ECE teachers in our sample were classified as obese, which is similar to a finding by the authors [8] where we found a $55 \%$ prevalence of obesity in a pre-pandemic study of ECE teachers. Further, only $39 \%$ of teachers met the recommended 150 min of moderate PA per week, which is higher than the 20\% reported for American adults aged between 18 and 65 years old by the Office of Disease Prevention and Health Promotion [84]. They spent, on average, $6.5 \mathrm{~h}$ a day being sedentary, which, when factoring in approximately $8 \mathrm{~h}$ of sleep, falls within the range from $50-60 \%$ of SB seen in the US adult population reported by Healy and colleagues [99]. Patterson et al. [18] suggest that from 6-8 h of sitting is a clear threshold of disease risk, and the US Department of Health and Human Services (HHS) [84] also reports a strong relationship between time in SB and the risk of all-cause mortality and cardiovascular disease mortality in adults. This said, the HHS also states that the degree of risk related to $\mathrm{SB}$ is dependent upon the amount of moderate-to-vigorous PA performed, which hints at the complex relationship between $\mathrm{PA}, \mathrm{SB}$, overall well-being, and life satisfaction revealed in our modeling.

The empirical test of our competing mediation models found the superior model was the model where teacher well-being mediated the association between PA and SB and life satisfaction compared to the model where PA and SB mediated the association between teacher well-being and life satisfaction. These findings add to the existing literature that high PA and low SB are associated with life satisfaction [52,58]. In our final model, all three aspects of teacher well-being (physical, psychological, and professional) mediated the relationship between PA and SB to life satisfaction. Previous research utilizing a multidimensional approach to understanding well-being found well-being explained substantial variation in key outcomes such as job satisfaction $(58.6 \%)$, organizational commitment (40.6\%), and life satisfaction (42.3\%) [47]. Although two of these outcomes were not measured in our study, we found our final model explained a similar amount of variation in life satisfaction for our sample of ECE teachers. Life satisfaction is impacted by a complex set of environmental, individual, and social factors. Identifying implementation strategies that focus on improving PA and SB as well as well-being (physical, psychological, and professional) will be important in improving this outcome. As previous research has found the type of PA (e.g., household, leisure, transportation) to be related to quality of life but not overall life satisfaction, and because minimal research has explored factors of well-being in ECE teachers, additional research examining more specific aspects of PA and its relationship to well-being and life satisfaction is warranted [29].

We observed two main indirect paths from PA (i.e., more than 150 min of moderate PA per week) to life satisfaction. The weaker of the two was through all three aspects of well-being measures (physical, psychological, and professional) and the stronger flowed through only physical and psychological well-being. The total indirect effects of PA on life satisfaction were significant as were the total indirect effects of SB on life satisfaction through physical, psychological, and professional well-being. These findings support research from others $[52,58]$ in that PA and SB are associated with higher life satisfaction, although effects measured in these studies were limited in younger adults [58]. These differences suggest there may be developmental differences throughout the life course or increase the importance of engaging in PA through middle and late adulthood, which has implications for the development of targeted interventions. Furthermore, the direct and indirect relationships found in this study between PA and SB and psychological well-being emphasize the importance of the role of PA on mental health and depression $[55,56,60]$.

Additionally observed, was a medium effect of the indirect path of physical well-being on life satisfaction through psychological well-being. An even larger effect was found in a direct path of psychological well-being on life satisfaction for this population, confirming the findings of Kardas and colleagues [49] who found that life satisfaction, along with 
gratitude, optimism, and hope, accounted for $51 \%$ of the variance in psychological wellbeing. The literature is unclear on the direction of these paths with regard to whether psychological well-being influences life satisfaction or whether life satisfaction influences psychological well-being. Our model confirmed that $150 \mathrm{~min}$ a week of moderate PA for ECE teachers was directly and positively associated with physical well-being, whereas SB was negatively associated with physical and psychological well-being. Thus, PA and SB remain modifiable supportive factors for ECE teachers and can improve overall physical well-being, decrease obesity, and hold lifestyle diseases at bay $[23,53,54]$. The increase in SB could also be partially explained within the context of the pandemic where almost half of the EC facilities closed, and equal percentages remained open or taught online leaving teachers prone to increased SB while teaching online or in their home environment and with limited to no access to fitness activities or facilities.

Our empirical test of the PA mediation model had a good, close fit, but was slightly inferior in fit to the well-being mediation model. Most importantly, however, the test of this model revealed no actual mediation. We surmise that this is due to the complex nature of PA on enhancing physical and psychological well-being and, ultimately, life satisfaction. Further, this suggests that PA, in the absence of enhanced psychological well-being, may have a limited impact on life satisfaction. These findings highlight the important role both PA and SB play in their well-being and life satisfaction. The findings are particularly important for ECE teachers, as previous research has found that these teachers have many health and well-being-related risks (e.g., obesity, depressive symptoms, perceived stress, [9]. Moreover, physically active ECE teachers would serve as role models and motivate children to be physically active [20-22].

\section{Limitations and Recommendations}

Caution is warranted in the application or generalization of our findings, however. First, it is important to note that our data were collected during the early months of the COVID-19 pandemic when stress and life disruptions were quite high and disproportionately impacted vulnerable populations, including ECE teachers [100]. Thus, it is likely that the typical associations we might see between PA, SB, well-being, and life satisfaction were also disrupted. Second, PA and SB were assessed with singular, self-reported items using a gross assessment of time. It is plausible and likely that more sensitive measures of movement, behaviors, and context would strengthen the findings and understanding of the complex nature of well-being. Indeed, our reliance on the self-reporting of information using the survey format was a limitation. Although self-report estimates of height are usually within 0.1 -inch accuracy, self-report of weight is typically underestimated by 4.6 pounds [101], and substantive variability exists in self-reporting of PA [102]. Moreover, given the variability in recommendations for PA and the dearth of suggestions for $\mathrm{SB}$, the benchmarks we used to determine thresholds-although evidence-informed-are somewhat tenuous. Further, information on PA and SB in our survey was assessed using estimates of time.

\section{Conclusions}

The overall conclusion of this analysis is that, while both models fit well, the model where teacher well-being was the mediator flowing through only physical and psychological well-being was superior. Of the 1234 ECE teachers who completed the online survey, over three quarters were overweight or obese, and just above a third of teachers met the recommended 150 min of moderate PA per week, which we found was positively associated with physical well-being and sedentary behavior was negatively associated with physical and psychological well-being. They have slight life satisfaction, experience moderate stress, and collectively, are approaching the threshold for depression yet still reflect moderate-to-high work commitment. Future studies to understand this somewhat counterintuitive finding is warranted. In our final model, all three aspects of teacher well-being (physical, psychological, and professional) mediated the relationship between 
PA and SB to life satisfaction. Since life satisfaction is influenced by a complex set of factors beyond those that we examined in this study, further research is warranted to determine the role that other factors, including environmental, individual, and social factors, can have on it. Given our findings of the direct and indirect relationships between PA, SB, and psychological well-being, as the pandemic subsides, we remain optimistic that PA and SB will remain modifiable risk factors for ECE teachers to improve their overall physical and psychological well-being, along with their life satisfaction.

Author Contributions: Conceptualization: K.-A.K., T.G.F. and K.R.; Methodology: K.-A.K. and T.G.F.; Software: T.G.F.; Validation: K.-A.K., K.R., M.R.B., D.D., S.S.S. and J.T.; Formal Analysis: T.G.F.; Investigation: K.-A.K., K.R., M.R.B., D.D., S.S.S. and J.T.; Data Curation: K.-A.K. and T.G.F.; WritingOriginal Draft Preparation: K.R., T.G.F. and K.-A.K.; Writing-Review and Editing: K.R., K.-A.K., T.G.F., M.R.B., D.D., S.S.S. and J.T.; Visualization: T.G.F.; Supervision: K.R.; Project Administration: K.-A.K. and K.R. All authors have read and agreed to the published version of the manuscript.

Funding: This research received no external funding.

Institutional Review Board Statement: The study was conducted according to the guidelines of the Declaration of Helsinki and approved by the Institutional Review Board of the University of Oklahoma (protocol code 12045, date of approval: 5 May 2020).

Informed Consent Statement: Informed consent was obtained from all subjects involved in the study.

Data Availability Statement: Data supporting reported results can be accessed by communicating by email with the corresponding author.

Conflicts of Interest: The authors declare no conflict of interest.

\section{References}

1. Ren, X. Pandemic and lockdown: A territorial approach to COVID-19 in China, Italy and the United States. Eurasian Geogr. Econ. 2020, 61, 423-434. [CrossRef]

2. Centers for Disease Control and Prevention. Interim List of Categories of Essential Workers Mapped to Standardized Industry Codes and Titles. Available online: https:/ / www.cdc.gov/vaccines/covid-19/categories-essential-workers.html (accessed on 4 June 2021).

3. Puccinelli, P.J.; da Costa, T.S.; Seffrin, A.; de Lira, C.A.B.; Vancini, R.L.; Nikolaidis, P.T.; Knechtle, B.; Rosemann, T.; Hill, L.; Andrade, M.S. Reduced level of physical activity during COVID-19 pandemic is associated with depression and anxiety levels: An internet-based survey. BMC Public Health 2021, 21, 1-11.

4. Stockwell, S.; Trott, M.; Tully, M.; Shin, J.; Barnett, Y.; Butler, L.; McDermott, D.; Schuch, F.; Smith, L. Changes in physical activity and sedentary behaviours from before to during the COVID-19 pandemic lockdown: A systematic review. BMJ Open Sport Exerc. Med. 2021, 7, e000960. [CrossRef]

5. Flanagan, E.W.; Beyl, R.A.; Fearnbach, S.N.; Altazan, A.D.; Martin, C.K.; Redman, L.M. The impact of COVID-19 stay-at-home orders on health behaviors in adults. Obesity 2021, 29, 438-445. [CrossRef] [PubMed]

6. Schuch, F.B.; Bulzing, R.A.; Meyer, J.; Vancampfort, D.; Firth, J.; Stubbs, B.; Grabovac, I.; Willeit, P.; Tavares, V.D.O.; Calegaro, V.C.; et al. Associations of moderate to vigorous physical activity and sedentary behavior with depressive and anxiety symptoms in self-isolating people during the COVID-19 pandemic: A cross-sectional survey in Brazil. Psychiatry Res. 2020, $292,113339$. [CrossRef] [PubMed]

7. Jeon, L.; Kwon, K.-A.; Choi, J.Y. Family child care providers' responsiveness toward children: The role of professional support and perceived stress. Child. Youth Serv. Rev. 2018, 94, 500-510. [CrossRef]

8. Kwon, K.-A.; Ford, T.; Salvatore, A.; Randall, K.; Jeon, L.; Malek-Lasater, A.; Ellis, N.; Kile, M.; Horm, D.; Kim, S.; et al. Neglected Elements of a High-Quality Early Childhood Workforce: Whole Teacher Well-Being and Working Conditions. Early Child. Educ. J. 2020, 1-12. [CrossRef]

9. Kwon, K.-A.; Ford, T.G.; Jeon, L.; Malek-Lasater, A.; Ellis, N.; Randall, K.; Kile, M.; Salvatore, A.L. Testing a holistic conceptual framework for early childhood teacher well-being. J. Sch. Psychol. 2021, 86, 178-197. [CrossRef]

10. Jeon, L.; Buettner, C.K.; Grant, A.A. Early childhood teachers' psychological well-being: Exploring potential predictors of depression, stress, and emotional exhaustion. Early Educ. Dev. 2018, 29, 53-69. [CrossRef]

11. Caspersen, C.J.; Powell, K.E.; Christenson, G.M. Physical activity, exercise, and physical fitness: Definitions and distinctions for health-related research. Public Health Rep. 1985, 100, 126-131.

12. Jetté, M.; Sidney, K.; Blümchen, G. Metabolic equivalents (METS) in exercise testing, exercise prescription, and evaluation of functional capacity. Clin. Cardiol 1990, 13, 555-565. [CrossRef] 
13. Tremblay, M.S.; LeBlanc, A.G.; Kho, M.E.; Saunders, T.J.; Larouche, R.; Colley, R.C.; Goldfield, G.; Gorber, S.C. Systematic review of sedentary behaviour and health indicators in school-aged children and youth. Int. J. Behav. Nutr. Phys. Act. 2011, 8, 1-22. [CrossRef]

14. American College of Sports, M.; Chodzko-Zajko, W.J.; Proctor, D.N.; Fiatarone Singh, M.A.; Minson, C.T.; Nigg, C.R.; Salem, G.J.; Skinner, J.S. American College of Sports Medicine position stand. Exercise and physical activity for older adults. Med. Sci. Sports Exerc. 2009, 41, 1510-1530.

15. McKinney, J.; Lithwick, D.J.; Morrison, B.N.; Nazzari, H.; Isserow, S.H.; Heilbron, B.; Krahn, A.D. The health benefits of physical activity and cardiorespiratory fitness. Br. Columbia Med. J. 2016, 58, 131-137.

16. Dunstan, D.; Barr, E.; Healy, G.; Salmon, J.; Shaw, J.; Balkau, B.; Magliano, D.; Cameron, A.; Zimmet, P.; Owen, N. Television viewing time and mortality: The Australian diabetes, obesity and lifestyle study (AusDiab). Circulation 2010, 121, 384-391. [CrossRef] [PubMed]

17. Katzmarzyk, P.T.; Church, T.S.; Craig, C.L.; Bouchard, C. Sitting time and mortality from all causes, cardiovascular disease, and cancer. Med. Sci. Sports Exerc. 2009, 41, 998-1005. [CrossRef]

18. Patterson, R.; McNamara, E.; Tainio, M.; de Sá, T.H.; Smith, A.D.; Sharp, S.J.; Edwards, P.; Woodcock, J.; Brage, S.; Wijndaele, K. Sedentary behaviour and risk of all-cause, cardiovascular and cancer mortality, and incident type 2 diabetes: A systematic review and dose response meta-analysis. Eur. J. Epidemiol. 2018, 33, 811-829. [CrossRef]

19. Carson, R.L.; Baumgartner, J.J.; Matthews, R.A.; Tsouloupas, C.N. Emotional exhaustion, absenteeism, and turnover intentions in childcare teachers: Examining the impact of physical activity behaviors. J. Health Psychol. 2010, 15, 905-914. [CrossRef]

20. Bruijns, B.A.; Adamo, K.B.; Burke, S.M.; Carson, V.; Irwin, J.D.; Naylor, P.-J.; Timmons, B.W.; Vanderloo, L.M.; Tucker, P. Early childhood education candidates' perspectives of their importance and responsibility for promoting physical activity and minimizing screen-viewing opportunities in childcare. J. Early Child. Teach. Educ. 2020, 1-18. [CrossRef]

21. Chen, C.; Ahlqvist, V.H.; Henriksson, P.; Magnusson, C.; Berglind, D. Preschool environment and preschool teacher's physical activity and their association with children's activity levels at preschool. PLoS ONE 2020, 15, e0239838. [CrossRef] [PubMed]

22. Fossdal, T.S.; Kippe, K.; Handegård, B.H.; Lagestad, P. “Oh oobe doo, I wanna be like you” associations between physical activity of preschool staff and preschool children. PLOS ONE 2018, 13, e0208001. [CrossRef]

23. United States Department of Health and Human Services. Physical Activity Guidelines for Americans, 2nd ed.; U.S. Department of Health and Human Services: Washington, DC, USA, 2018.

24. Ward, D.S.; Vaughn, A.E.; Hales, D.; Viera, A.J.; Gizlice, Z.; Bateman, L.A.; Grummon, A.H.; Arandia, G.; Linnan, L.A. Workplace health and safety intervention for child care staff: Rationale, design, and baseline results from the CARE cluster randomized control trial. Contemp. Clin. Trials 2018, 68, 116-126. [CrossRef] [PubMed]

25. Levy, S. Definitional Framework for the Concept of Well-Being. In Encyclopedia of Quality of Life and Well-Being Research; Michalos, A.C., Ed.; Springer: Dordrecht, The Netherlands, 2014; pp. 1489-1493.

26. Capio, C.M.; Sit, C.H.P.; Abernethy, B. Physical Well-Being. In Encyclopedia of Quality of Life and Well-Being Research; Michalos, A.C., Ed.; Springer: Dordrecht, The Netherlands, 2014; pp. 4805-4807.

27. Delle Fave, A. Eudaimonic and Hedonic Happiness. In Encyclopedia of Quality of Life and Well-Being Research; Michalos, A.C., Ed.; Springer: Dordrecht, The Netherlands, 2014; pp. 1999-2004.

28. Wald, J.; Taylor, S.; Asmundson, G.J.; Jang, K.; Stapleton, J.A. Literature Review of Concepts: Psychological Resiliency; Defence R\&D: Toronto, ON, Canada, 2006.

29. Hall-Kenyon, K.M.; Bullough, R.V.; MacKay, K.L.; Marshall, E.E. Preschool teacher well-being: A review of the literature. Early Child. Educ. J. 2014, 42, 153-162. [CrossRef]

30. Kong, F.; Gong, X.; Sajjad, S.; Yang, K.; Zhao, J. How Is Emotional Intelligence Linked to Life Satisfaction? The Mediating Role of Social Support, Positive Affect and Negative Affect. J. Happiness Stud. 2019, 20, 2733-2745. [CrossRef]

31. Lombardo, P.; Jones, W.; Wang, L.; Shen, X.; Goldner, E.M. The fundamental association between mental health and life satisfaction: Results from successive waves of a Canadian national survey. BMC Public Health 2018, 18, 342. [CrossRef]

32. Testa, M.A.; Simonson, D.C. Assessment of quality-of-life outcomes. N. Engl. J. Med. 1996, 334, 835-840. [CrossRef] [PubMed]

33. Wiese, C.W.; Kuykendall, L.; Tay, L. Get active? A meta-analysis of leisure-time physical activity and subjective well-being. J. Posit. Psychol. 2018, 13, 57-66. [CrossRef]

34. Lessard, L.M.; Wilkins, K.; Rose-Malm, J.; Mazzocchi, M.C. The health status of the early care and education workforce in the USA: A scoping review of the evidence and current practice. Public Health Rev. 2020, 41, 1-17. [CrossRef]

35. Dev, D.A.; McBride, B.A. Academy of Nutrition and Dietetics benchmarks for nutrition in child care 2011: Are child-care providers across contexts meeting recommendations? J. Acad. Nutr. Diet. 2013, 113, 1346-1353. [CrossRef]

36. Linnan, L.; Arandia, G.; Bateman, L.A.; Vaughn, A.; Smith, N.; Ward, D. The Health and Working Conditions of Women Employed in Child Care. Int. J. Environ. Res. Public Health 2017, 14, 283. [CrossRef]

37. Otten, J.J.; Bradford, V.A.; Stover, B.; Hill, H.D.; Osborne, C.; Getts, K.; Seixas, N. The Culture of Health in Early Care and Education: Workers' Wages, Health, And Job Characteristics. Health Aff. 2019, 38, 709-720. [CrossRef]

38. Whitaker, R.; Becker, D.; Herman, A.N.; Gooze, R.A. The physical and mental health of Head Start staff: The Pennsylvania Head Start staff wellness survey. Prev. Chronic Dis. 2012, 10, E181. [CrossRef]

39. Hamre, B.K.; Pianta, R.C. Self-reported depression in nonfamilial caregivers: Prevalence and associations with caregiver behavior in child-care settings. Early Child. Res. Q. 2004, 19, 297-318. [CrossRef] 
40. McLean, L.; Connor, C.M. Depressive symptoms in third-grade teachers: Relations to classroom quality and student achievement. Child Dev. 2015, 86, 945-954. [CrossRef] [PubMed]

41. Roberts, A.; LoCasale-Crouch, J.; Hamre, B.; DeCoster, J. Exploring teachers' depressive symptoms, interaction quality, and children's social-emotional development in Head Start. Early Educ. Dev. 2016, 27, 642-654. [CrossRef]

42. Sandilos, L.E.; Cycyk, L.M.; Hammer, C.S.; Sawyer, B.E.; López, L.; Blair, C. Depression, Control, and Climate: An Examination of Factors Impacting Teaching Quality in Preschool Classrooms. Early Educ. Dev. 2015, 26, 1111-1127. [CrossRef]

43. Collie, R.J.; Malmberg, L.-E.; Martin, A.J.; Sammons, P.; Morin, A.J. A multilevel person-centered examination of teachers' workplace demands and resources: Links with work-related well-being. Front. Psychol. 2020, 11, 626. [CrossRef]

44. Zinsser, K.M.; Bailey, C.S.; Curby, T.W.; Denham, S.A.; Bassett, H.H. Exploring the predictable classroom: Preschool teacher stress, emotional supportiveness, and studentsâ $€^{\mathrm{TM}}$ social-emotional behavior in private and Head Start classrooms. NHSA Dialog. 2013, $16,90-108$.

45. Herman, K.C.; Hickmon-Rosa, J.E.; Reinke, W.M. Empirically derived profiles of teacher stress, burnout, self-efficacy, and coping and associated student outcomes. J. Posit. Behav. Interv. 2018, 20, 90-100. [CrossRef]

46. Jeon, L.; Hur, E.; Buettner, C.K. Child-care chaos and teachers' responsiveness: The indirect associations through teachers' emotion regulation and coping. J. Sch. Psychol. 2016, 59, 83-96. [CrossRef]

47. Kern, M.L.; Waters, L.; Adler, A.; White, M. Assessing employee wellbeing in schools using a multifaceted approach: Associations with physical health, life satisfaction, and professional thriving. Psychology 2014, 5, 500-513. [CrossRef]

48. Colomeischi, A.A. Teachers' Life Satisfaction and Wellbeing: Engagement Influences. In Studies and Current Trends in Science of Education; Editura Lumen, Asociatia Lumen: Suceava, Romania, 2017; pp. 139-150.

49. Kardas, F.; Zekeriya, C.; Eskisu, M.; Gelibolu, S. Gratitude, hope, optimism and life satisfaction as predictors of psychological well-being. Eurasian J. Educ. Res. 2019, 19, 81-100. [CrossRef]

50. Bano, S.; Malik, S. Effect of Occupational Stress on Life Satisfaction among Private and Public School Teachers. J. Indep. Stud. Res.-Manag. Soc. Sci. Econ. 2014, 12, 17-27. [CrossRef]

51. Sheffield, D.; Dobbie, D.; Carroll, D. Stress, social support, and psychological and physical wellbeing in secondary school teachers. Work Stress 1994, 8, 235-243. [CrossRef]

52. Pengpid, S.; Peltzer, K. Sedentary Behaviour, Physical Activity and Life Satisfaction, Happiness and Perceived Health Status in University Students from 24 Countries. Int. J. Environ. Res. Public Health 2019, 16, 2084. [CrossRef]

53. Burke, L.; Ma, J.; Azar, K.; Bennett, G.; Peterson, E.; Zheng, Y.; Riley, W.; Stephens, J.; Shah, S.; Suffoletto, B.; et al. Current Science on Consumer Use of Mobile Health for Cardiovascular Disease Prevention: A Scientific Statement from the American Heart Association. Circulation 2015, 132, 1157-1213. [CrossRef]

54. Sallis, R.; Franklin, B.; Joy, L.; Ross, R.; Sabgir, D.; Stone, J. Strategies for promoting physical activity in clinical practice. Prog. Cardiovasc. Dis. 2015, 57, 375-386. [CrossRef]

55. Saxena, S.; Van Ommeren, M.; Tang, K.C.; Armstrong, T.P. Mental health benefits of physical activity. J. Ment. Health 2005, 14, 445-451. [CrossRef]

56. Brown, W.J.; Ford, J.H.; Burton, N.W.; Marshall, A.L.; Dobson, A.J. Prospective Study of Physical Activity and Depressive Symptoms in Middle-Aged Women. Am. J. Prev. Med. 2005, 29, 265-272. [CrossRef]

57. Parra-Rizo, M.A.; Sanchis-Soler, G. Satisfaction with Life, Subjective Well-Being and Functional Skills in Active Older Adults Based on Their Level of Physical Activity Practice. Int. J. Environ. Res. Public Health 2020, 17, 1299. [CrossRef]

58. Maher, J.P.; Pincus, A.L.; Ram, N.; Conroy, D.E. Daily physical activity and life satisfaction across adulthood. Dev. Psychol. 2015, 51, 1407-1419. [CrossRef] [PubMed]

59. Ginoux, C.; Isoard-Gautheur, S.; Teran-Escobar, C.; Forestier, C.; Chalabaev, A.; Clavel, A.; Sarrazin, P. Being active during the lockdown: The recovery potential of physical activity for well-being. Int. J. Environ. Res. Public Health 2021, 18, 1707. [CrossRef]

60. Nowak, P.F.; Bożek, A.; Blukacz, M. Physical Activity, Sedentary Behavior, and Quality of Life among University Students. BioMed Res. Int. 2019, 2019, 9791281. [CrossRef] [PubMed]

61. Giuntella, O.; Hyde, K.; Saccardo, S.; Sadoff, S. Lifestyle and mental health disruptions during COVID-19. Proc. Natl. Acad. Sci. USA 2021, 118, e2016632118. [CrossRef]

62. Cheval, B.; Sivaramakrishnan, H.; Maltagliati, S.; Fessler, L.; Forestier, C.; Sarrazin, P.; Orsholits, D.; Chalabaev, A.; Sander, D.; Ntoumanis, N.; et al. Relationships between changes in self-reported physical activity, sedentary behaviour and health during the coronavirus (COVID-19) pandemic in France and Switzerland. J. Sports Sci. 2021, 39, 699-704. [CrossRef]

63. Meyer, J.; McDowell, C.; Lansing, J.; Brower, C.; Smith, L.; Tully, M.; Herring, M. Changes in Physical Activity and Sedentary Behavior in Response to COVID-19 and Their Associations with Mental Health in 3052 US Adults. Int. J. Environ. Res. Public Health 2020, 17, 6469. [CrossRef]

64. Chen, S.; Calderón-Larrañaga, A.; Saadeh, M.; Dohrn, I.M.; Welmer, A.K. Correlations of subjective and social wellbeing with sedentary behavior and physical activity in older adults-A population-based study. J. Gerontol. A Biol. Sci. Med. Sci. 2021. [CrossRef]

65. Kleszczewska, D.; Szkutnik, A.M.; Siedlecka, J.; Mazur, J. Physical Activity, Sedentary Behaviours and Duration of Sleep as Factors Affecting the Well-Being of Young People against the Background of Environmental Moderators. Int. J. Environ. Res. Public Health 2019, 16, 915. [CrossRef] 
66. Wang, F.; Boros, S. The relationship between physical activity, stress, life satisfaction and sleep quality. J. Phys. Educ. Sport 2019, 19, 227-234.

67. Park, J.H.; Moon, J.H.; Kim, H.J.; Kong, M.H.; Oh, Y.H. Sedentary Lifestyle: Overview of Updated Evidence of Potential Health Risks. Korean J. Fam. Med. 2020, 41, 365-373. [CrossRef] [PubMed]

68. Whitebook, M.; Mclean, C.; Austin, L.J.E.; Edwards, B. The Early Childhood Workforce Index 2018. Available online: https: / / cscce.berkeley.edu/early-childhood-workforce-2018-index/ (accessed on 5 December 2020).

69. Ware, J.E.; Kosinski, M.; Keller, S.D.; New England Medical Center; Health Assessment. SF-12: How to Score the SF-12 Physical and Mental Health Summary Scales; Quality Metric Inc.: Lincoln, NE, USA; Health Assessment Lab: Boston, MA, USA, 2002.

70. Failde, I.; Medina, P.; Ramirez, C.; Arana, R. Construct and criterion validity of the SF-12 health questionnaire in patients with acute myocardial infarction and unstable angina. J. Eval. Clin. Pract. 2010, 16, 569-573. [CrossRef] [PubMed]

71. Bohannon, R.W.; Maljanian, R.; Landes, M. Test-retest reliability of short form (SF)-12 component scores of patients with stroke. Int. J. Rehabil. Res. 2004, 27, 149-150. [CrossRef] [PubMed]

72. Booth, M. Assessment of Physical Activity: An International Perspective. Res. Q. Exerc. Sport 2000, 71 (Suppl. 2), $114-120$ [CrossRef] [PubMed]

73. Craig, C.L.; Marshall, A.L.; Sjöström, M.; Bauman, A.E.; Booth, M.L.; Ainsworth, B.E.; Pratt, M.; Ekelund, U.; Yngve, A.; Sallis, J.F.; et al. International physical activity questionnaire: 12-country reliability and validity. Med. Sci. Sports Exerc. 2003, 35, 1381-1395. [CrossRef] [PubMed]

74. Kathy Cheng, H.Y.; Cheng, C.Y.; Ju, Y.Y. Work-related musculoskeletal disorders and ergonomic risk factors in early intervention educators. Appl. Ergon. 2013, 44, 134-141. [CrossRef]

75. Diener, E.; Emmons, R.A.; Larsen, R.J.; Griffin, S. The Satisfaction with Life Scale. J. Pers. Assess 1985, 49, 71-75. [CrossRef]

76. Eaton, W.W.; Smith, C.; Ybarra, M.; Muntaner, C.; Tien, A. Center for Epidemiologic Studies Depression Scale: Review and Revision (CESD and CESD-R). In The Use of Psychological Testing for Treatment Planning and Outcomes Assessment: Instruments for Adults, 3rd ed.; Lawrence Erlbaum Associates Publishers: Mahwah, NJ, USA, 2004; Volume 3, pp. 363-377.

77. Baron, E.C.; Davies, T.; Lund, C. Validation of the 10-item Centre for Epidemiological Studies Depression Scale (CES-D-10) in Zulu, Xhosa and Afrikaans populations in South Africa. BMC Psychiatry 2017, 17, 1-14. [CrossRef]

78. Björgvinsson, T.; Kertz, S.J.; Bigda-Peyton, J.S.; McCoy, K.L.; Aderka, I.M. Psychometric properties of the CES-D-10 in a psychiatric sample. Assessment 2013, 20, 429-436. [CrossRef]

79. Cohen, S.; Kamarck, T.; Mermelstein, R. A global measure of perceived stress. J. Health Soc. Behav. 1983, 24, 385-396. [CrossRef]

80. Jorde-Bloom, P. Factors Influencing Overall Job Satisfaction and Organizational Commitment in Early Childhood Work Environments. J. Res. Child. Educ. 1988, 3, 107-122. [CrossRef]

81. Wagner, B.D.; French, L. Motivation, Work Satisfaction, and Teacher Change Among Early Childhood Teachers. J. Res. Child. Educ. 2010, 24, 152-171. [CrossRef]

82. Stremmel, A.J. Predictors of intention to leave child care work. Early Child. Res. Q. 1991, 6, 258-298. [CrossRef]

83. United States Department of Agriculture, Economic Research Service. US Household Food Security Survey Module: Six-Item Short Form. Available online: https:/ / www.ers.usda.gov/media/8282/short2012.pdf (accessed on 4 May 2021).

84. Office of Disease Prevention and Health Promotion. Healthy People 2020: Topics \& Objectives-Physical Activity. Available online: https:/ / www.healthypeople.gov/2020/topics-objectives/topics/physical-activity (accessed on 5 May 2021).

85. Du, Y.; Liu, B.; Sun, Y.; Snetselaar, L.G.; Wallace, R.B.; Bao, W. Trends in adherence to the physical activity guidelines for Americans for aerobic activity and time spent on sedentary behavior among US adults, 2007 to 2016. JAMA Netw. Open 2019, 2, e197597. [CrossRef]

86. Hamilton, M.T.; Healy, G.N.; Dunstan, D.W.; Zderic, T.W.; Owen, N. Too little exercise and too much sitting: Inactivity physiology and the need for new recommendations on sedentary behavior. Curr. Cardiovasc. Risk Rep. 2008, 2, 292-298. [CrossRef] [PubMed]

87. Tremblay, M.S.; Rollo, S.; Saunders, T.J. Sedentary Behavior Research Network members support new Canadian 24-Hour Movement Guideline recommendations. J. Sport Health Sci. 2020, 9, 479. [CrossRef]

88. Andresen, E.M.; Malmgren, J.A.; Carter, W.B.; Patrick, D.L. Screening for depression in well older adults: Evaluation of a short form of the CES-D (Center for Epidemiologic Studies Depression Scale). Am. J. Prev. Med. 1994, 10, 77-84. [CrossRef]

89. Smith, B.W.; Dalen, J.; Wiggins, K.; Tooley, E.; Christopher, P.; Bernard, J. The Brief Resilience Scale: Assessing the ability to bounce back. Int. J. Behav. Med. 2008, 15, 194-200. [CrossRef] [PubMed]

90. Stamm, B.H. Professional Quality of Life: Compassion Satisfaction and Fatigue Version 5 (ProQOL). 2009. Available online: http:/ / compassionfatigue.org/pages/ProQOLManualOct05.pdf: (accessed on 5 July 2021).

91. Huisman, M. Imputation of Missing Item Responses: Some Simple Techniques. Qual. Quant. 2000, 34, 331-351. [CrossRef]

92. Karasek, R.; Brisson, C.; Kawakami, N.; Houtman, I.; Bongers, P.; Amick, B. The Job Content Questionnaire (JCQ): An instrument for internationally comparative assessments of psychosocial job characteristics. J. Occup. Health Psychol. 1998, 3, 322-355. [CrossRef]

93. Enders, C.K. Applied Missing Data Analysis; Guilford Press: New York, NY, USA, 2010.

94. Kline, R.B. Principles and Practice of Structural Equation Modeling, 4th ed.; Guilford Press: New York, NY, USA, 2016.

95. Hu, L.-T.; Bentler, P.M. Evaluating model fit. In Structural Equation Modeling: Concepts, Issues, and Applications; Sage Publications, Inc.: Thousand Oaks, CA, USA, 1995; pp. 76-99. 
96. Hagell, P.; Alvariza, A.; Westergren, A.; Årestedt, K. Assessment of Burden Among Family Caregivers of People with Parkinson's Disease Using the Zarit Burden Interview. J. Pain Symptom. Manag. 2017, 53, 272-278. [CrossRef]

97. Berrington de Gonzalez, A.; Hartge, P.; Cerhan, J.R.; Flint, A.J.; Hannan, L.; MacInnis, R.J.; Moore, S.C.; Tobias, G.S.; Anton-Culver, H.; Freeman, L.B.; et al. Body-Mass Index and Mortality among 1.46 Million White Adults. N. Engl. J. Med. 2010, 363, $2211-2219$. [CrossRef] [PubMed]

98. Hu, L.; Bentler, P.M. Cutoff criteria for fit indexes in covariance structure analysis: Conventional criteria versus new alternatives. Struct. Equ. Model. A Multidiscip. J. 1999, 6, 1-55. [CrossRef]

99. Healy, G.N.; Matthews, C.E.; Dunstan, D.W.; Winkler, E.A.; Owen, N. Sedentary time and cardio-metabolic biomarkers in US adults: NHANES 2003-06. Eur. Heart J. 2011, 32, 590-597. [CrossRef] [PubMed]

100. Crawford, A.; Vaughn, K.A.; Guttentag, C.L.; Varghese, C.; Oh, Y.; Zucker, T.A. “Doing What I can, but I got no Magic Wand": A Snapshot of Early Childhood Educator Experiences and Efforts to Ensure Quality During the COVID-19 Pandemic. Early Child. Educ. J. 2021, 49, 829-840. [CrossRef] [PubMed]

101. Brunner Huber, L.R. Validity of self-reported height and weight in women of reproductive age. Matern. Child Health J. 2007, 11, 137-144. [CrossRef]

102. Baranowski, T.; Smith, M.; Thompson, W.O.; Baranowski, J.; Hebert, D.; de Moor, C. Intraindividual variability and reliability in a 7-day exercise record. Med. Sci. Sports Exerc. 1999, 31, 1619-1622. [CrossRef] [PubMed] 